\title{
In situ preparation of thermoset/clay nanocomposites via thiol-epoxy click chemistry
}

\author{
Ozlem Purut Koc ${ }^{1} \cdot$ Seda Bekin Acar ${ }^{1}$ - Tamer Uyar ${ }^{2}$ • \\ Mehmet Atilla Tasdelen ${ }^{1}$ (D)
}

\begin{abstract}
A series of thermoset/clay nanocomposites are prepared by thiol-epoxy click reaction using commercially available starting compounds at ambient conditions in very good yields. The incorporation and exfoliation of clay nanolayers in the thermoset matrix are confirmed by FT-IR, XRD and TEM analyses. The influence of clay loadings on the thermal and mechanical analyses is investigated and all nanocomposites exhibit improved properties than that of the pristine thermoset. The nanocomposite containing $1 \%$ montmorillonite by weight has the most improved mechanical properties due to its highly exfoliated structure resulting in efficient interactions between clay and polymer matrix. A further increase of the clay loading results in the aggregation of clay plates to form intercalated structures leading to deteriorated thermal and mechanical properties of nanocomposites.
\end{abstract}

Keywords Click chemistry · Nanocomposites · Nanoclay · Thermoset · Thiolepoxy reaction

\section{Introduction}

Polymer/clay nanocomposites are one kind of composite materials containing nanometer-sized inorganic nanoparticles, typically in the range of 1-100 nm, which are uniformly dispersed in and fixed to a polymer matrix [1]. Because of their superior physical properties such as high dimensional stability, gas barrier

Mehmet Atilla Tasdelen

tasdelen@yalova.edu.tr

1 Department of Polymer Engineering, Faculty of Engineering, Yalova University, 77200 Yalova, Turkey

2 UNAM-Institute of Materials Science and Nanotechnology, Bilkent University, 06800 Ankara, Turkey 
performance, flame retardancy, and mechanical strength, their applications have been expanded continuously in the fields of automotive, cable packaging and coating [2]. The inclusion of inorganic nanoclays into a polymer matrix not only combines their properties but also brings advanced new functions in many industrial applications. Depending on the starting materials and processing techniques, there are three approaches for the preparation of polymer/clay nanocomposites: (i) solution mixing, (ii) melt blending and (iii) in situ polymerization. By applying these methods, three distinct morphologies can be possibly obtained; exfoliated (delaminated), intercalated (flocculated) and unintercalated (microcomposite) [3]. Compared to the first two approaches, the in situ polymerization method is an effective method to obtain nanocomposites with exfoliated structures that are responsible for the dramatic improvements in the physical properties [4]. In this method, the organo-modified clay containing either monomer [5, 6] or initiator [7-9] functionalities are mixed with a suitable liquid monomer solution prior to polymerization [10-12]. By applying appropriate stimulus, such as heat, light or chemical activation, the chain growth as well as the delamination of the clay galleries can be triggered and hence the corresponding nanocomposite is formed [13]. Click chemistry is a general term that identifies a class of chemical reactions to generate substances rapidly and reliably by connecting molecules from reactive groups that will only connect with one another [14]. Due to its unique features including simplicity, efficiency and orthogonally, it has been widely used in the diverse applications from organic chemistry to polymer and material science $[15,16]$. The well-known click chemistry reactions are: (i) cycloaddition reactions [copper (I)catalyzed azide-alkyne (CuAAC) and Diels-Alder], (ii) ring-opening reactions (epoxides and aziridines), (iii) non-aldol reactions (ureas, oximes, and hydrazones) and (iv) addition reactions (thiol-ene/yne and Michael). Recently, base-catalyzed ring-opening reaction of an epoxide with a thiol is classified as click chemistry reaction due to its exceptional features such as selectivity, controllability, simplicity, fastness, and high efficiency [17]. Compared to other click reactions, it has additional advantages such as metal-free catalyst system and resulting product containing reactive hydroxyl groups that enable further functionalization. This click reaction is utilized not only in polymer synthesis [18, 19] such as synthesis of thermosets [20, 21], hybrid network [22-24], hydrogels [25] and high-performance coatings [26-28], but also in functionalization of polymers [29-31]. For the preparation of polymer/clay nanocomposites, only used click reaction is CuAAC click reaction, in which alkyne-functionalized monomers or prepolymers [32, 33] are clicked azido-functionalized nanoclay, independently [34].

Thermoset polymers are bonded covalently and cannot be melted by heating or dissolved completely in any solvent because of their three-dimensional cross-linked structures [35]. They have been utilized for the preparation of many important advanced materials, such as protective coatings, aerospace composites and computer chip packaging due to their attractive properties (good strength, well chemical resistance and high temperature stability) [36]. On the other hand, thermoset materials can have brittleness and lack of durability in their final properties. So, thermoset nanocomposites have been evolved to eliminate these shortcomings. Because of its desirable characteristics, thiol-epoxy click reaction has 
been utilized for the preparation of hyper-branched epoxy [37] and polyester [38] and complex multi-layered microdevices [39] using commercially available monomers. A facile way to improve physical properties of thermoset is to produce their composites or nanocomposites using appropriate reinforcements. The use of nanosized fillers with high aspect ratio such as clays, nanotubes and nanoparticles has intensively developed due to their unique multifunctional and highly enhanced properties.

In this study, clay-based thermoset nanocomposites have been prepared by thiolepoxy click chemistry using trimethylolpropane triglycidyl ether and trimethylolpropane tris(3-mercaptopropionate) as commercially available monomers and montmorillonite (Cloisite 30B) as nanofiller. The thiol-epoxy click reaction can be simply catalyzed by lithium hydroxide and conducted in the presence of air and water at ambient temperature and pressure. The obtained polymer/clay nanocomposites have been characterized by Fourier-transform infrared (FT-IR) spectroscopy, X-ray diffraction (XRD) spectroscopy, transmission electron microscopy (TEM) and thermogravimetric analysis (TGA). The influence of clay loadings on thermal and mechanical properties of the resulting polymer/clay nanocomposites is also investigated.

\section{Experimental}

\section{Materials}

The organo-modified montmorillonite (Cloisite 30B was an alkyl quaternary ammonium salt bentonite) was purchased from Southern Clay Products and kept in a vacuum oven for $1 \mathrm{~h}$ at $110^{\circ} \mathrm{C}$ before using as nanofiller. Trimethylolpropane triglycidyl ether (TTE, technical grade, Aldrich), trimethylolpropane tris(3mercaptopropionate) (TMPMP $\geq 95.0 \%$, Aldrich), and lithium hydroxide monohydrate ( $\mathrm{LiOH} 99.95 \%$, Aldrich) were used as received. Tetrahydrofuran (THF, $99.9 \%$, Aldrich) and deionized water were used as solvents.

\section{Preparation of thermoset/clay nanocomposites via thiol-epoxy click chemistry}

The TMPMP (1.52 mmol, $0.605 \mathrm{~g})$ and TTE (1.52 mmol, $0.46 \mathrm{~g})$ with various clay loadings $(0,1,5$ or $10 \%$ by weight $)$ in $\mathrm{THF}(4.5 \mathrm{~mL})$ were stirred with a magnetic stirrer at room temperature. $\mathrm{LiOH}(0.55 \mathrm{mmol}, 23 \mathrm{mg})$ dissolved in distilled water $(0.5 \mathrm{~mL})$ was added to the resulting solution by stirring according to a modified procedure [25]. To obtain completely homogeneous mixture, the solution was further stirred for few minutes. The solutions containing 1, 5 or $10 \%$ clay were poured into glass Petri dishes and nanocomposite structures were rapidly obtained after $5 \mathrm{~min}$ as a result of exothermic reactions. The samples (NC-1, NC-5 or NC-10) were dried in a vacuum oven for $24 \mathrm{~h}$ at $50{ }^{\circ} \mathrm{C}$ before the characterization to eliminate the remaining water and THF on the determined properties. 


\section{Instrumentation}

Fourier-transform infrared (FT-IR) spectra were recorded on a Perkin-Elmer FT-IR Spectrum One B spectrometer. The powder XRD measurements were performed on a PANalytical X'Pert PRO X-ray diffractometer equipped with graphite-monochromatized $\mathrm{Cu} \mathrm{K}$-alpha radiation $(\lambda=0.115 \mathrm{~nm})$. The thermogravimetric analysis was conducted by Perkin-Elmer Diamond TA/TGA with a heating rate of $10{ }^{\circ} \mathrm{C} / \mathrm{min}$ under nitrogen flow $(200 \mathrm{~mL} / \mathrm{min})$. Transmission electron microscopy (TEM) observation was utilized by a FEI Tecnai ${ }^{\mathrm{TM}} \mathrm{G}^{2} \mathrm{~F} 30$ instrument operating at an acceleration voltage of $200 \mathrm{kV}$. The ultrathin TEM specimens around $100 \mathrm{~nm}$ were cut by a cryo-ultramicrotome $\left(\mathrm{EMUC}_{6}+\mathrm{EMFC}_{6}\right.$, Leica) equipped with a diamond knife. Before TEM analyses, the obtained specimens were located on holey carboncoated grid. The tensile properties of samples were determined with a Zwick/Roell Z1.0 universal test machine at room temperature according to the DIN EN ISO $527-1$ standard with the crosshead speed of $5 \mathrm{~mm} / \mathrm{min}$. The sample specimens were cut into rectangular bars with $7.4 \mathrm{~mm} \times 20 \mathrm{~mm} \times 10 \mathrm{~mm}$ dimensions. For each sample, at least three specimens were tested to provide reproducibility.

\section{Results and discussion}

To take advantages of thiol-epoxy click reaction, a series of thermoset nanocomposites containing 1, 5 and $10 \%$ nanoclay by weight were prepared using Cloisite 30B as organo-modified nanoclay with TMPMP and TTE as commercially available monomers. All reactions were activated by $\mathrm{LiOH}$ as a base-catalyst and carried out at room temperature. Due to their highly strained three-membered rings, epoxides are very reactive towards a large range of nucleophiles, alcohols, alkoxides, amines and thiols, and easily converted corresponding compounds in basic and acidic conditions. To benefit from this chemistry, a series of thermoset/clay nanocomposites were simply prepared by simultaneous base-catalyzed thiol-epoxy and alcoholepoxy ring-opening reactions. The epoxy rings of TTE were opened via two competitive reactions by either thiol groups of TMPMP or alcohol groups of Cloisite 30B (containing one methyl and tallow groups, and two pendant alcohol groups $\left(-\mathrm{CH}_{2} \mathrm{CH}_{2} \mathrm{OH}\right)$ on the quaternary ammonium ions) in the presence of $\mathrm{LiOH}$ (Scheme 1).

The formation of nanocomposites was monitored by FT-IR analysis by following their characteristic bands of epoxide and thiol groups of initial compounds, which were assigned at 910 and $2680 \mathrm{~cm}^{-1}$. After ring-opening reactions, these bands were completely disappeared, whereas a new peak, appeared at $3400 \mathrm{~cm}^{-1}$, was attributed to $\mathrm{O}-\mathrm{H}$ bond closest to thioether group. Furthermore, the weak absorption band at $2570 \mathrm{~cm}^{-1}$ assigned to S-H bond of TMPMP was not detected in the nanocomposite's spectrum (Fig. 1). Additionally, the peaks at 2890, 1740 and $1100 \mathrm{~cm}^{-1}$ were assigned to $\mathrm{C}-\mathrm{H}, \mathrm{C}=\mathrm{O}$ and $\mathrm{C}-\mathrm{O}-\mathrm{C}$ bonds, clearly indicating the presence of initial compounds in the nanocomposites. Overall, the successful thiolepoxy click reaction in the presence of organo-modified clays yielded to thermoset 

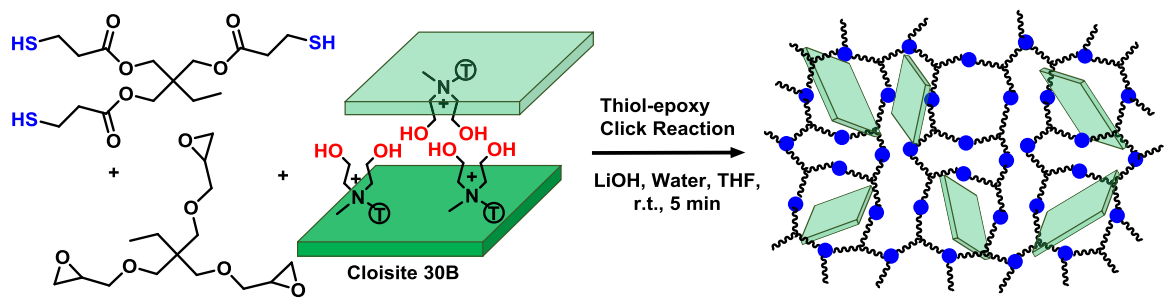

Tis tallow ( $65 \% \mathrm{C} 18 ; \sim 30 \% \mathrm{C} 16 ; \sim 5 \% \mathrm{C} 14)$.

Thermoset/Clay Nanocomposites
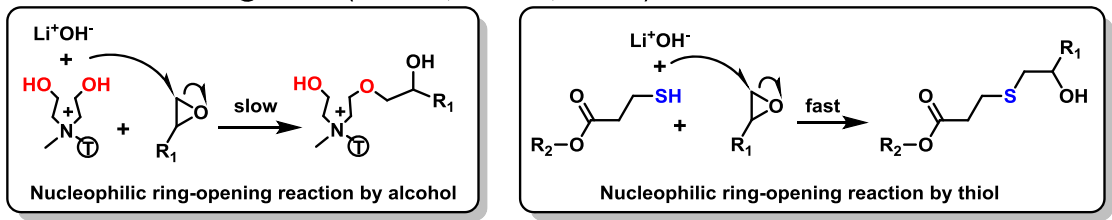

Scheme 1 Thermoset/clay nanocomposites by simultaneous base-catalyzed thiol-epoxy and alcoholepoxy ring-opening reactions using Cloisite 30B as nanoclay and TTE and TMPMP as monomers

Fig. 1 FT-IR spectra of initial TTE and TMPMP compounds and resulting nanocomposites (NC-10 containing $10 \%$ clay by weight)
Fig. 2 XRD spectra of Cloisite $30 \mathrm{~B}$ and resulting nanocomposites (NC-1, NC-5 and $\mathrm{NC}-10)$
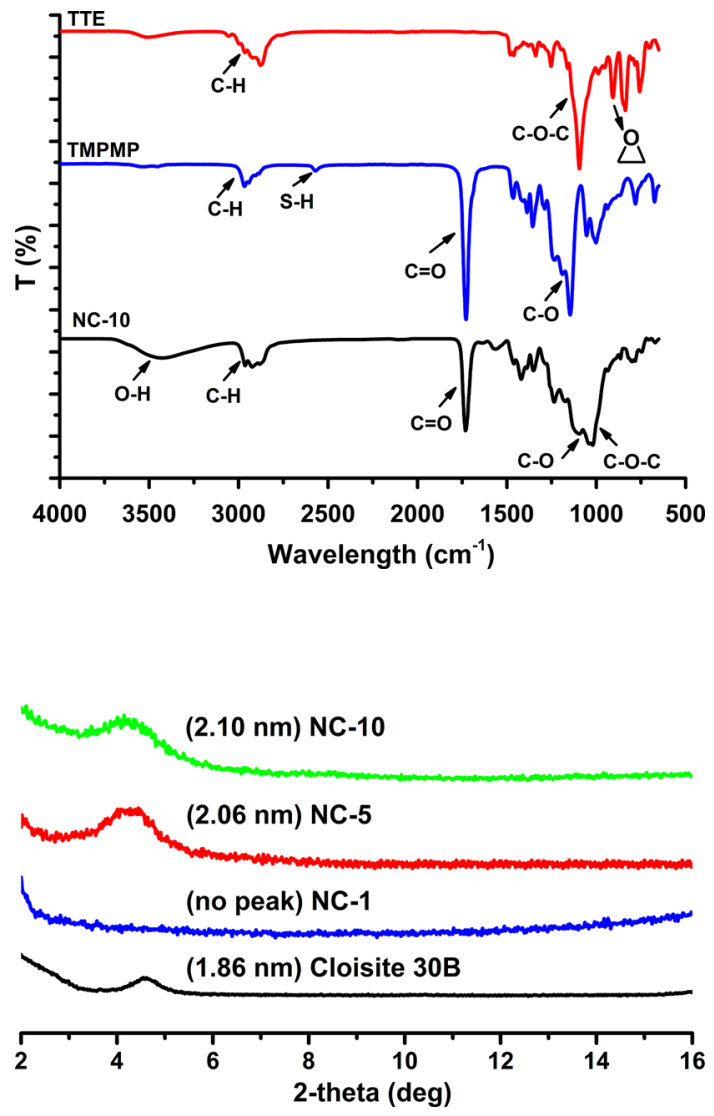
networks containing aliphatic $(\mathrm{C}-\mathrm{H})$, thioether $(\mathrm{C}-\mathrm{S}-\mathrm{C})$, ester $[(\mathrm{C}=\mathrm{O})-\mathrm{O}]$ and alcohol $(\mathrm{O}-\mathrm{H})$ groups according to FT-IR analysis.

The X-ray diffraction patterns of commercial clay (Cloisite 30B) and obtained nanocomposites with various clay loadings (1, 5 and $10 \%$ by weight) are shown in Fig. 2. In the XRD pattern of Cloisite $30 \mathrm{~B}$, there was a weak peak at $2 \theta=4.81^{\circ}$, and it indicated that the distance between clay layers was about $1.86 \mathrm{~nm}$. However, there was no peak in the X-ray diffractogram of NC-1, so it was estimated that almost all clay layers were exfoliated and dispersed randomly in thermoset matrix. When the clay loadings were over $1 \%$, a similar peak at low angle was detected for both NC-5 and NC-10 samples. There was no apparent difference between the XRD patterns of NC-5 and NC-10, and the distances between clay plates were calculated as 2.06 and $2.10 \mathrm{~nm}$, respectively. This observation indicated a coexistence of intercalated or intercalated/exfoliated clay layers in the nanocomposites. In the polymer/clay nanocomposite preparation, the clay layers exhibited strong polar interactions that were critical to the formation of intercalated and exfoliated morphologies [40-42]. By increasing clay loadings, the silicate layers were stacked on each other and held together through intensive ionic attractions and, therefore, intercalated or mixed intercalated/exfoliated structures were formed in the thermoset matrix.

To get more detailed information on the clay dispersions, the morphologies of $\mathrm{NC}-1$ and NC-5 samples were investigated by transmission electron microscopy. In Fig. 3, the dark lines were assigned as clay layers, whereas the bright areas represented thermoset matrix. In the both samples, TEM analysis revealed that mixed exfoliated/intercalated morphologies were attained upon addition of nanoclay. The observed individual clay layers (highlighted by yellow circles) were well dispersed (delaminated) in the polymer matrix, while the large intercalated tactoids (highlighted by red rectangles) were visible in NC-1 and NC-5. Although the most of the clay layers were locally stacked, some of them were isolated from
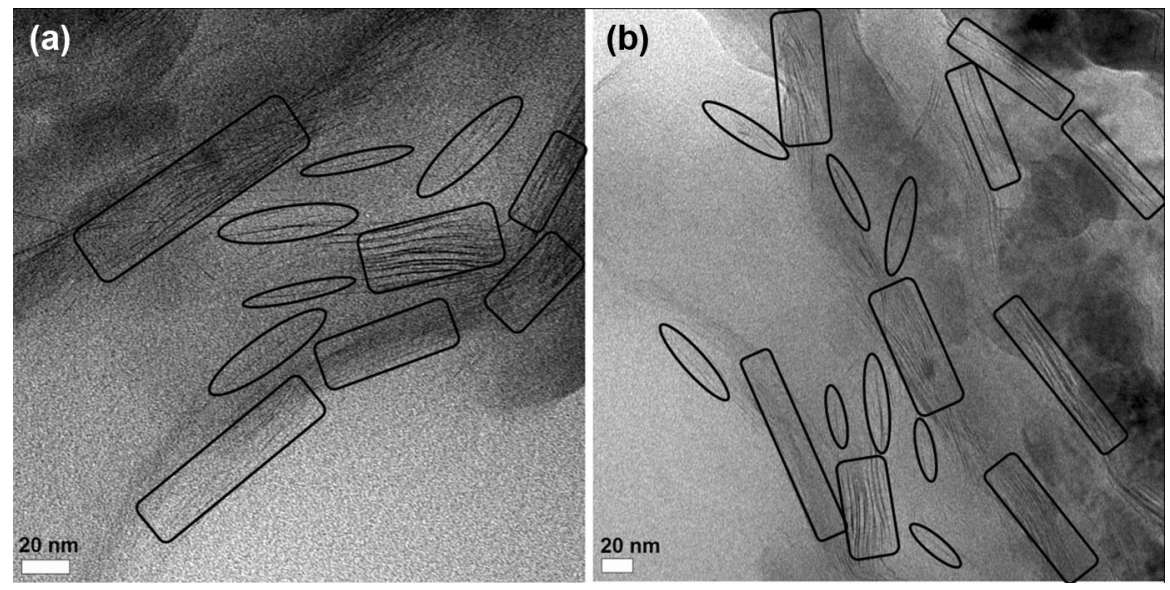

Fig. 3 TEM micrographs of NC-1 (a) and NC-5 (b) in low magnifications (circle as exfoliated layers and rectangles layers as intercalated, scale bar: $20 \mathrm{~nm}$ ) 
any stack and randomly dispersed in the polymer matrix [43-45]. The coexistence of partially exfoliated/intercalated structures proposed that the van der Waals and Coulombic forces between silicate layers as well as their high specific surface area and surface energy tending to keep them tightly rather than to disperse homogeneously. Overall, combined XRD and TEM results confirmed that the resulting nanocomposites had partially mixed exfoliated/intercalated morphologies.

Thermal behaviors of nanocomposites were investigated by thermogravimetric (TGA) and derivative thermogravimetry (DTG) analyses and compared with neat thermoset sample that was prepared in the absence of Cloisite 30B under identical conditions (Fig. 4). All samples showed one-step degradation implying the bond cleavages of $\mathrm{C}-\mathrm{O}-\mathrm{C}, \mathrm{C}-\mathrm{S}, \mathrm{C}-\mathrm{H}$ and $\mathrm{C}-\mathrm{C}$ in the range of $220-500{ }^{\circ} \mathrm{C}$. In addition, this decomposition caused an entire degradation of the organic part of nanocomposites and provided the formation of stable, carbonaceous and inorganic residues as a char. The amounts of residual char yields were 3.9, 5.6, 11.8 and $17.5 \%$ for neat thermoset polymer, NC-1, NC-5 and NC-10, respectively. This increment was attributed to the incorporation of inorganic clays in thermoset matrix causing the restriction of movement of polymer chains. According to the TGA and DTG results, the maximum decomposition temperature was first increased from $323{ }^{\circ} \mathrm{C}$ (neat thermoset) to $339{ }^{\circ} \mathrm{C}$ (NC-1) and then was decreased to $327{ }^{\circ} \mathrm{C}$ (NC-5) and $328^{\circ} \mathrm{C}$ (NC-10). This trend could be explained by morphologies of the nanocomposites, in which NC-1 had highest exfoliated structures according to TEM and XRD analyses. On the other hand, the increase of intercalated structures in the nanocomposites could slightly reduce the thermal stabilities of nanocomposite (NC-5 and NC-10). However, all nanocomposites exhibited improved thermal stabilities compared to neat thermoset sample.

The influence of clay loadings on the mechanical properties of nanocomposites was also investigated by a universal tensile test machine. The amount of clay nanoparticles in the polymer matrix played a crucial role in determining the mechanical properties of prepared nanocomposite structures. As expected from previous studies, there was a tendency that tensile modulus was increased by
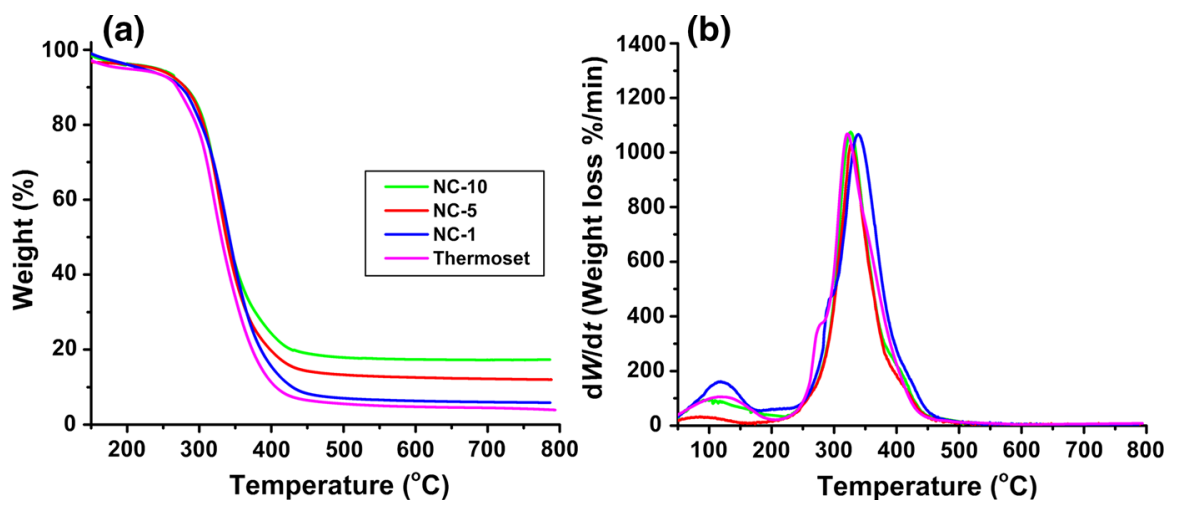

Fig. 4 TGA (a) and DTG (b) thermograms of neat thermoset and resulting nanocomposites (NC-1, NC-5 and $\mathrm{NC}-10)$ 
increasing clay contents, whereas elongation at break was conversely decreased [41, 42, 46]. This decrease could be also associated with the plasticization effects of residual water on the clay layers. From the stress-strain curves shown in Fig. 5, the tensile strength and elongation at break values of nanocomposites were significantly increased in comparison with the neat thermoset sample. Among the nanocomposite samples, the NC-1 was the most improved mechanical properties due to its highexfoliated structures providing efficient interactions between clay and polymer matrix. For high clay contents, mechanical properties of nanocomposites were deteriorated in both cases, but still higher than that of the neat thermoset sample in the absence of clay. It was consistent with the literature findings that a large amount of clay gave rise to a decrease in the mechanical properties due to heterogeneous dispersion and aggregation of clay resulting in poor interfacial interactions between clay layers and thermoset network. Consequently, the increase in clay contents not only resulted in an improvement on rigidity and elastic modulus, but also lowered elongation at break.

\section{Conclusions}

In conclusion, thermoset/clay nanocomposites from commercially available monomers and organoclay were prepared via thiol-epoxy click reaction under ambient conditions using lithium hydroxide as catalyst at room temperature. The combined XRD and TEM analyses indicated that the obtained nanocomposites had a mixed exfoliated/intercalated morphology. In addition, the thermal and mechanical properties of these nanocomposites were considerably improved compared to the pristine thermoset polymer. Among them, the NC-1 had the most improved

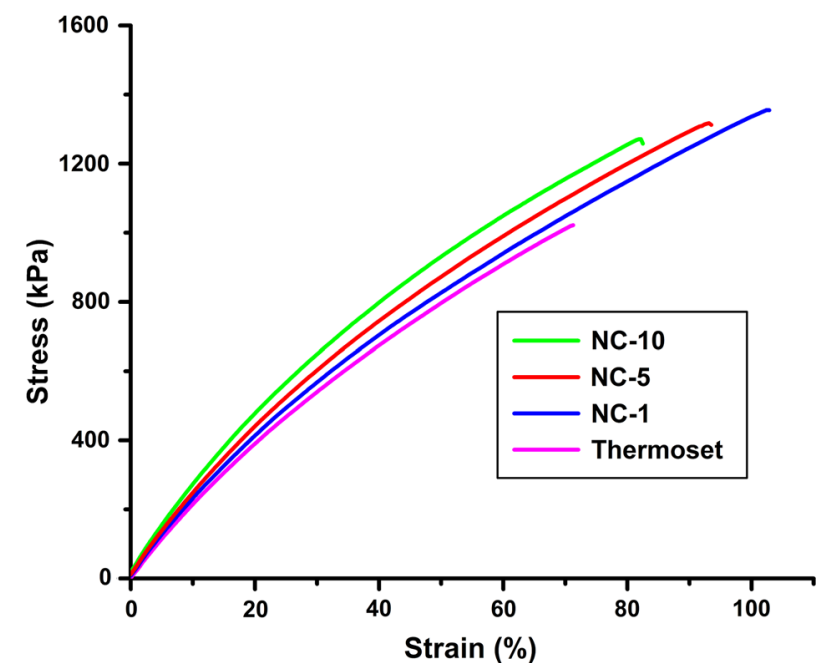

Fig. 5 Stress (\%)-strain (kPa) curves of neat thermoset and resulting nanocomposites (NC-1, NC-5 and NC-10) 
mechanical properties due to its highly exfoliated structures resulting in efficient interactions between clay and polymer matrix.

Acknowledgements The authors would like to thank Yalova University Research Fund (Project no: 2015/YL/055) for financial supports.

\section{References}

1. Ray SS, Okamoto M (2003) Polymer/layered silicate nanocomposites: a review from preparation to processing. Prog Polym Sci 28(11):1539-1641. https://doi.org/10.1016/j.progpolymsci.2003.08.002

2. Pavlidou S, Papaspyrides C (2008) A review on polymer-layered silicate nanocomposites. Prog Polym Sci 33(12):1119-1198. https://doi.org/10.1016/j.progpolymsci.2008.07.008

3. Kotal M, Bhowmick AK (2015) Polymer nanocomposites from modified clays: recent advances and challenges. Prog Polym Sci 51:127-187. https://doi.org/10.1016/j.progpolymsci.2015.10.001

4. Tasdelen MA, Kreutzer J, Yagci Y (2010) In situ synthesis of polymer/clay nanocomposites by living and controlled/living polymerization. Macromol Chem Phys 211(3):279-285. https://doi.org/10. 1002/macp.200900590

5. Dizman C, Ates S, Uyar T, Tasdelen MA, Torun L, Yagci Y (2011) Polysulfone/clay nanocomposites by in situ photoinduced crosslinking polymerization. Macromol Mater Eng 296(12):1101-1106. https://doi.org/10.1002/mame.201100114

6. Karamane M, Raihane M, Tasdelen MA, Uyar T, Lahcini M, Ilsouk M, Yagci Y (2017) Preparation of fluorinated methacrylate/clay nanocomposite via in situ polymerization: characterization, structure, and properties. J Polym Sci A 55(3):411-418. https://doi.org/10.1002/pola.28403

7. Altinkok C, Uyar T, Tasdelen MA, Yagci Y (2011) In situ synthesis of polymer/clay nanocomposites by type II photoinitiated free radical polymerization. J Polym Sci A 49(16):3658-3663. https://doi. org/10.1002/pola.24788

8. Aydin M, Atilla Tasdelen M, Uyar T, Yagci Y (2013) In situ synthesis of A3-type star polymer/clay nanocomposites by atom transfer radical polymerization. J Polym Sci A 51(24):5257-5262. https:// doi.org/10.1002/pola.26957

9. Ozkose UU, Altinkok C, Yilmaz O, Alpturk O, Tasdelen MA (2017) In-situ preparation of poly (2ethyl-2-oxazoline)/clay nanocomposites via living cationic ring-opening polymerization. Eur Polym J 88:586-593. https://doi.org/10.1016/j.eurpolymj.2016.07.004

10. Wang X, Su Q, Shan JH, Zheng JP (2016) The effect of clay modification on the mechanical properties of poly(methyl methacrylate)/organomodified montmorillonite nanocomposites prepared by in situ suspension polymerization. Polym Compos 37(6):1705-1714. https://doi.org/10.1002/pc. 23343

11. Assem Y, Khalaf AI, Rabia AM, Yehia AA, Zidan TA (2016) Synthesis and characterization of hybrid clay/poly ( $N, N$-dimethylaminoethyl methacrylate) nanocomposites. Polym Compos 37(10):2950-2959. https://doi.org/10.1002/pc.23492

12. Oral A, Tasdelen MA, Demirel AL, Yagci Y (2009) Poly(cyclohexene oxide)/clay nanocomposites by photoinitiated cationic polymerization via activated monomer mechanism. J Polym Sci A 47(20):5328-5335. https://doi.org/10.1002/pola.23581

13. Aydin M, Uyar T, Tasdelen MA, Yagci Y (2015) Polymer/clay nanocomposites through multiple hydrogen-bonding interactions. J Polym Sci A 53(5):650-658. https://doi.org/10.1002/pola.27487

14. Kolb HC, Finn MG, Sharpless KB (2001) Click chemistry: diverse chemical function from a few good reactions. Angew Chem Int Ed 40(11):2004-2021. https://doi.org/10.1002/15213773(20010601)40:11<2004:AID-ANIE2004>3.0.CO;2-5

15. Nandivada H, Jiang XW, Lahann J (2007) Click chemistry: versatility and control in the hands of materials scientists. Adv Mater 19(17):2197-2208. https://doi.org/10.1002/adma.200602739

16. Binder WH, Sachsenhofer R (2008) 'Click' chemistry in polymer and material science: an update. Macromol Rapid Commun 29(12-13):952-981. https://doi.org/10.1002/marc.200800089

17. Stuparu MC, Khan A (2016) Thiol-epoxy "click" chemistry: application in preparation and postpolymerization modification of polymers. J Polym Sci A 54(19):3057-3070. https://doi.org/10.1002/ pola. 28195 
18. De S, Khan A (2012) Efficient synthesis of multifunctional polymers via thiol-epoxy "click" chemistry. Chem Commun 48(25):3130-3132. https://doi.org/10.1039/c2cc30434a

19. Binder S, Gadwal I, Bielmann A, Khan A (2014) Thiol-epoxy polymerization via an AB monomer: synthetic access to high molecular weight poly(beta-hydroxythio-ether)s. J Polym Sci A 52(14):2040-2046. https://doi.org/10.1002/pola.27212

20. Guzman D, Ramis X, Fernandez-Francos X, Serra A (2015) Enhancement in the glass transition temperature in latent thiol-epoxy click cured thermosets. Polymers 7(4):680-694. https://doi.org/10. 3390/polym7040680

21. Acebo C, Fernandez-Francos X, Ramis X, Serra A (2016) Thiol-yne/thiol-epoxy hybrid crosslinked materials based on propargyl modified hyperbranched poly(ethyleneimine) and diglycidylether of bisphenol A resins. RSC Adv 6(66):61576-61584. https://doi.org/10.1039/c6ra13158a

22. Acar SB, Ozcelik M, Uyar T, Tasdelen MA (2017) Polyhedral oligomeric silsesquioxane-based hybrid networks obtained via thiol-epoxy click chemistry. Iran Polym J 26(6):405-411. https://doi. org/10.1007/s13726-017-0529-x

23. Gorkem Sencevik R, Atilla Tasdelen M (2014) Poly (methyl methacrylate)/POSS hybrid networks by type II photoinitiated free radical polymerization. Polym Compos 35(8):1614-1620. https://doi.org/ 10.1002/pola.27487

24. Arslan I, Tasdelen MA (2016) POSS-based hybrid thermosets via photoinduced copper-catalyzed azide-alkyne cycloaddition click chemistry. Des Monomers Polym 19(2):155-160. https://doi.org/10. 1080/15685551.2015.1124323

25. Cengiz N, Rao JY, Sanyal A, Khan A (2013) Designing functionalizable hydrogels through thiolepoxy coupling chemistry. Chem Commun 49(95):11191-11193. https://doi.org/10.1039/ c3cc45859h

26. Fernandez-Francos X, Konuray AO, Belmonte A, De la Flor S, Serra A, Ramis X (2016) Sequential curing of off-stoichiometric thiol-epoxy thermosets with a custom-tailored structure. Polym Chem 7(12):2280-2290. https://doi.org/10.1039/c6py00099a

27. Guzman D, Ramis X, Fernandez-Francos X, Serra A (2015) Preparation of click thiol-ene/thiolepoxy thermosets by controlled photo/thermal dual curing sequence. RSC Adv 5(123):101623-101633. https://doi.org/10.1039/c5ra22055f

28. Guzman D, Ramis X, Fernandez-Francos X, Serra A (2014) New catalysts for diglycidyl ether of bisphenol A curing based on thiol-epoxy click reaction. Eur Polym J 59:377-386. https://doi.org/10. 1016/j.eurpolymj.2014.08.001

29. Brandle A, Khan A (2012) Thiol-epoxy 'click' polymerization: efficient construction of reactive and functional polymers. Polym Chem 3(12):3224-3227. https://doi.org/10.1039/c2py20591b

30. Gadwal I, Khan A (2013) Protecting-group-free synthesis of chain-end multifunctional polymers by combining ATRP with thiol-epoxy 'click' chemistry. Polym Chem 4(8):2440-2444. https://doi.org/ 10.1039/c3py00136a

31. Acebo C, Fernandez-Francos X, Ramis X, Serra A (2016) Multifunctional allyl-terminated hyperbranched poly(ethyleneimine) as component of new thiol-ene/thiol-epoxy materials. React Funct Polym 99:17-25. https://doi.org/10.1016/j.reactfunctpolym.2015.12.003

32. Tasdelen MA (2011) Poly(epsilon-caprolactone)/clay nanocomposites via "click" chemistry. Eur Polym J 47(5):937-941. https://doi.org/10.1016/j.eurpolymj.2011.01.004

33. Tasdelen MA, Van Camp W, Goethals E, Dubois P, Du Prez F, Yagci Y (2008) Polytetrahydrofuran/clay nanocomposites by in situ polymerization and "click" chemistry processes. Macromolecules 41(16):6035-6040. https://doi.org/10.1021/ma801149x

34. Arslan M, Tasdelen MA (2017) Polymer nanocomposites via click chemistry reactions. Polymers 9(10):499. https://doi.org/10.3390/polym9100499

35. Raquez JM, Deleglise M, Lacrampe MF, Krawczak P (2010) Thermosetting (bio)materials derived from renewable resources: a critical review. Prog Polym Sci 35(4):487-509. https://doi.org/10.1016/j. progpolymsci.2010.01.001

36. Yousefi A, Lafleur PG, Gauvin R (1997) Kinetic studies of thermoset cure reactions: a review. Polym Compos 18(2):157-168. https://doi.org/10.1002/pc.10270

37. Zhang DH, Liu CH, Chen SF, Zhang JH, Cheng J, Miao MH (2016) Highly efficient preparation of hyperbranched epoxy resins by UV-initiated thiol-ene click reaction. Prog Org Coat 101:178-185. https://doi.org/10.1016/j.porgcoat.2016.08.010

38. Flores M, Tomuta AM, Fernandez-Francos X, Ramis X, Sangermano M, Serra A (2013) A new twostage curing system: thiol-ene/epoxy homopolymerization using an allyl terminated hyperbranched 
polyester as reactive modifier. Polymer 54(21):5473-5481. https://doi.org/10.1016/j.polymer.2013. 07.056

39. Sticker D, Rothbauer M, Lechner S, Hehenberger MT, Ertl P (2015) Multi-layered, membraneintegrated microfluidics based on replica molding of a thiol-ene epoxy thermoset for organ-on-a-chip applications. Lab Chip 15(24):4542-4554. https://doi.org/10.1039/c5lc01028d

40. Mohan T, Ramesh Kumar M, Velmurugan R (2005) Rheology and curing characteristics of epoxyclay nanocomposites. Polym Int 54(12):1653-1659. https://doi.org/10.1002/pi.1897

41. Piscitelli F, Scamardella AM, Romeo V, Lavorgna M, Barra G, Amendola E (2012) Epoxy composites based on amino-silylated MMT: the role of interfaces and clay morphology. J Appl Polym Sci 124(1):616-628. https://doi.org/10.1002/app.35015

42. Lan T, Kaviratna PD, Pinnavaia TJ (1995) Mechanism of clay tactoid exfoliation in epoxy-clay nanocomposites. Chem Mater 7(11):2144-2150. https://doi.org/10.1021/cm00059a023

43. Osman MA, Mittal V, Morbidelli M, Suter UW (2004) Epoxy-layered silicate nanocomposites and their gas permeation properties. Macromolecules 37(19):7250-7257. https://doi.org/10.1002/pc. 23397

44. Brown JM, Curliss D, Vaia RA (2000) Thermoset-layered silicate nanocomposites. Quaternary ammonium montmorillonite with primary diamine cured epoxies. Chem Mater 12(11):3376-3384. https://doi.org/10.1021/cm000477+

45. Morgan AB, Gilman JW (2003) Characterization of polymer-layered silicate (clay) nanocomposites by transmission electron microscopy and X-ray diffraction: a comparative study. J Appl Polym Sci 87(8):1329-1338. https://doi.org/10.1002/app.11884

46. Sanchez-Cabezudo M, Prolongo MG, Salom C, del Cid MAG, Masegosa RM (2016) Ternary nanocomposites: curing, morphology, and mechanical properties of epoxy/thermoplastic/organoclay systems. Polym Compos 37(7):2184-2195. https://doi.org/10.1002/pc.23397 